the priority should be getting the patient in good time to an intensive care unit experienced in the respiratory and circulatory problems presented by the disease.

Headington,

J M K SPALDing

Oxford OX3 $8 \mathrm{~TB}$

${ }^{1}$ Landry.JBO. Note sur la paralysie ascendante aiguë. Gazette Hebdomadaire des Médicales de Paris 1859;6:472-4.

${ }^{2}$ Guillain G, Barré JA, Strohl A. Sur un syndrome de radiculo-névrite avec hyperalbuminose du liquide cephalo-rachidien sans reaction cellulaire. Remarques sur les caractères cliniques et graphiques des réflexes tendineux. Bulletins et mémoires de la société médicale des hôpitaux de Paris 1916;40:1462-70.

${ }^{3}$ Castaigne P, Brunet P, Nouailhat F. Enquête clinique sur les polyradiculonévrites inflammatoires en France. Rev Neurol (Paris) 1966; $115: 849-72$.

${ }^{4}$ Hewer RL, Hilton PJ, Smith AC, Spalding JMK. Acute polyneuritis requiring artificial respiration. $Q \mathcal{F}$ Med 1968;37:479-91.

5 Masucci EF, Kurtzke JG. Diagnostic criteria for the Guillain-Barré syndrome. An analysis of 50 cases. F Neurol Sci $1971 ; 13: 483-501$.

${ }^{6}$ Hughes RAC, Newsom-Davis JM, Perkin GD, Pierce JM. Controlled trial of prednisolone in acute polyneuropathy. Lancet 1978;ii:750-3.

7 Asbury A, Fisher R, McKhann GM, Mobley W, Server A. Guillain-Barré syndrome: is there a role for plasmapheresis? Neurology (NY) 1980; 30:1112.

${ }^{8}$ Schonberger LB, Bregman DJ, Sullivan Bolyai JZ, et al. Guillain-Barré syndrome following vaccination in the National Influenza Immunisation Program, United States, 1976-77. Am f Epidemiol 1979;110:105-23.

${ }^{9}$ Marks JS, Halpin TJ. Guillain-Barré syndrome in recipients of A/New Jersey influenza vaccine. $\mathcal{F} A M A 1980 ; 243: 2490-4$.

${ }^{10}$ Hurwitz ES, Schonberger LB, Nelson DB, Holman RC. Guillain-Barré syndrome and the 1978-1979 influenza vaccine. N Engl f Med 1981; 304:1557-61.

\section{Assessment of insomnia}

Insomnia or, more strictly, expressed dissatisfaction with the duration or quality of sleep is most common in women and in older age groups. ${ }^{12}$ If of recent onset, then history taking will generally uncover causal circumstances in the patient's life or occasionally a depressive illness. More often the complaint is longstanding.

A recent paper from Detroit outlined the evaluation of 84 patients in a clinic for the investigation of sleep disorders. ${ }^{3}$ The authors assert that not only should such patients have a psychiatric, psychological, and general medical evaluation but also that "polysomnography" is necessary. This mixture of Greek and Latin will not appeal to all, but the claim merits examination. It contrasts, perhaps embarrassingly, with the recent conclusion by our own Committee on Review of Medicines ${ }^{4}$ that intractable insomnia is an indication for barbiturates (despite the disproportionately high death rate from these drugs among older patients). ${ }^{5}$

The American authors divided the 84 patients into 10 diagnostic categories, ${ }^{6}$ including psychiatric disorder, disorder related to drug or alcohol use, respiratory impairments, and disorders of circadian rhythm. Groups of insomniacs usually include nearly twice as many women as men, but on this occasion $60 \%$ were men; and no fewer than $20 \%$ were classified as suffering from the restless legs syndrome or nocturnal myoclonus. The patients seem to have been an atypical group of insomniacs. Furthermore, classification of a patient as, for example, one whose legs jerk at night should not imply that the jerks cause the complaint of insomnia. People complaining of insomnia rarely relate it to their bodily functions. A recent survey of 296 insomniacs with an average age of 46 years, complaining on average for 11 years, set out to examine whether the insomnia was attributed by the complainers to bodily disorders or to feelings of mental arousal; and the results strongly favoured arousal. ${ }^{7}$

The North American attempt to attribute insomnia to disturbing somatic disorders reflects an attitude to sleep mechanisms. When new discoveries about the reticular formation were being made in the 1960s the idea grew up that sleep was essentially a passive phenomenon that supervened when there was nothing to keep the brain alert. By the 1970 s the idea that sleep is induced and maintained as a positive process came back. A comparison of patterns of sleep that had been broken for two different reasonsbecause of ingestion of caffeine and as a consequence of the withdrawal of hypnotic drugs-led to the proposal ${ }^{8}$ that two kinds of insomnia could be distinguished- "too much waking or not enough sleep." Withdrawal of drugs seemed to cause a weakness of the sleep process itself in contrast with the disturbance caused by caffeine.

Behind the school of thought that argues that insomnia must be investigated lurks an assumption that, but for some disturbing factor, the patient would not only sleep but be pleased with the sleep. Alas, some people are not easy to please. Some patients are discontented and manipulative in seeking for attention, sympathy, and "treatment" in the form of barbiturates or other hypnotic and anxiety-relieving drugs. Many general practitioners are uneasy with these demandsand themselves avoid the patients and allow their secretaries to write most of the prescriptions. ${ }^{9}$

"Polysomnographic" investigations are expensive and generally cannot distinguish between people who have complaints about their sleep and people of the same age who do not. Furthermore, the chief tool, electroencephalography, tells us nothing about the restorative value of the sleep. ${ }^{10}$ Most people who complain of insomnia are older people, and as they grow older there is a steady increase in the brokenness of sleep and a steady fall in the amount of slow-wave sleep (often regarded as the most restorative). We must assume that both these changes that parallel age reflect the age of the brain $^{11} 12$ rather than that new sleep-disturbing factors affect older people.

The doctor faced with a patient who complains of insomnia should rely primarily on the clinical history. If the patient is also sleepy by day, or if there are cramps at bedtime, or if strange events in the night are reported by a spouse, then special investigation may be warranted. But who should undertake them? In Britain we would turn to a neurologist or psychiatrist with broad clinical experience. Clinical neurophysiologists might more often make their aid available. In the United States much money was invested in research into sleep in the 1960s. Ten years on the money ran out, and the research workers-expert in a narrow field and with healthy young people-looked for new support. The solution came with the belief (not wholly convincing) that sleep researchers could be rapidly transmuted into experts in the investigating and treating of sleep disorders. The special clinics that have sprung up around the United States would be better justified if there were more treatments of proved merit.

The position of many of these new clinics remains controversial even in the United States-indeed, one of the longstanding groups has stated that referral of the vast majority of patients with sleep disorders to special clinics "is not only unnecessary, but often it is not in the patient's best interests. The use of highly sophisticated and highly expensive procedures and the close attention to polygraphic sleep patterns often render little information of clinical importance." $13 \mathrm{We}$ may agree with this group that the general practitioner is the 
best person to diagnose and manage most sleep disorders. $\mathrm{He}$ is in the best position to recognise those of his patients who need support through their middle and later years, when complaints about sleep will be only part of a larger picture, which he is the most likely person to understand.

IAN OsWALD

Professor of Psychiatry,

University of Edinburgh

${ }^{1}$ McGhie A, Russell SM. The subjective assessment of normal sleep patterns. F Ment Sci 1962;108:642-54.

${ }^{2}$ Bixler EO, Kales A, Soldatos CR, Kales JD, Healey S. Prevalence of sleep disorders in the Los Angeles metropolitan area. Am $\mathcal{F}$ Psychiatry $1979 ; 136: 1257-62$.

${ }^{3}$ Zorick FJ, Roth T, Hartze KM, Piccione PM, Stepanski EJ. Evaluation and diagnosis of persistent insomnia. Am F Psychiatry 1981;138:769-73.

4 Committee on the Review of Medicines. Recommendations on barbiturate preparations. $\mathrm{Br}$ Med $\mathcal{F} 1979 ; \mathrm{ii}: 719-20$.

${ }^{5}$ Johns MW. Self-poisoning with barbiturates in England and Wales during 1959-74. Br Med f 1977;i:1128-30.

6 Association of Sleep Disorders Centers and the Association for the Psychophysiological Study of Sleep. Disorders of initiating and maintaining sleep (insomnias). Sleep 1979;2:21-57.

' Lichstein KL, Rosenthal TL. Insomniacs' perceptions of cognitive versus somatic determinants of sleep disturbance. 7 Abnorm Psychol $1980 ; 89: 105-7$

${ }^{8}$ Březinová V, Oswald I, Loudon J. Two types of insomnia: too much waking or not enough sleep. Br f Psychiatry 1975;126:439-45.

${ }^{9}$ Freed A. Prescribing of tranquillisers and barbiturates by general practitioners. $\mathrm{Br}$ Med $\mathcal{F} 1976$;ii:1232-3.

${ }^{10}$ Adam K. Do drugs alter the restorative value of sleep ? In: Passouant $P$, Oswald I, eds. Pharmacology of the states of alertness. Oxford: Pergamon Press, 1979:105-11.

11 Feinberg I, Koresko RL, Heller N. EEG sleep patterns as a function of normal and pathological aging in man. $\mathcal{F}$ Psychiatr Res 1967;5:107-44.

12 Březinová $V$. The number and duration of the episodes of the various EEG stages of sleep in young and older people. Electroencephalogr Clin Neurophysiol 1975;39:273-8.

${ }^{13}$ Kales JD, Kales A, Bixler EO, Soldatos CR. Resource for managing sleep disorders. $\mathcal{F} A M A 1979 ; 241: 2413-6$

\section{Transdermal drug administration-a nuisance becomes an opportunity}

Skin is not as impenetrable an organ as is often believed: while it forms an effective barrier against invasion of the body by micro-organisms and protects against loss of body water, it will allow transdermal permeation of topically applied creams and ointments ${ }^{1}$ in quantities sufficient to have a systemic action. Topical steroids have been a major advance in dermatology ${ }^{2}$ but their systemic side effects are potentially serious because of their disturbance of the pituitary-adrenal axis..$^{3-5}$ Systemic side effects have also been reported with the use of $1 \%$ gamma benzene hexachloride for scabies and pediculi, ${ }^{6}$ and from bismuth-containing creams, ${ }^{7}$ phenylephrine, ${ }^{8}$ salicylic acid, ${ }^{9} 10$ and hexachlorophane. ${ }^{11}$

What factors, then, govern the transdermal permeation of drugs through skin? What is the relative permeation through intact and damaged skin ? and Why are these systemic reactions manifest only occasionally and often not at all ? The scientific basis for current understanding of the permeability of skin to different solutes was laid by Scheuplein. ${ }^{12-15}$ Many substances with adequate solubility in oil and water and molecular weights below 800-1000 can permeate across skin. ${ }^{16}$ Definition of the factors responsible for variable and apparently unpredictable transdermal absorption was essential before the skin could be used as a dependable route for absorption of drugs. Absorption varies within and between individuals in response to alterations in the concentration of the solute applied to the skin, the use of a different vehicle, the intactness of the stratum corneum, the extent of inflammation of the skin, the age of the skin, ethnic skin differences, regional skin differences in permeability, and the areas of skin covered. ${ }^{17}$

Systemic drug administration by the transdermal route is now part of therapeutics. In the United States and various European countries preparations of nitroglycerin, ${ }^{18}$ etofenamate, ${ }^{19}$ and 17 -beta-oestradiol ${ }^{20}$ are now available for application to the skin for systemic treatment. The rate of systemic drug absorption from these preparations is variable, mostly because of the wide range in the area of application by the patient. In the absence of specific directions patients are left to apply the drug to enough skin to obtain the effect sought, but not to so much skin as to result in a rate of absorption that causes side effects. The duration of systemic action is mainly controlled by the thickness of the layer of the ointment or cream applied.

The pharmaceutical industry is now focusing interest on drug-delivery systems that provide a defined rate of drug release over a prescribed time-so-called therapeutic systems. ${ }^{21}$ Adhesive drug-containing films of defined surface area deliver the drug to the surface of the intact skin at a preprogrammed rate. This rate is such that the system, and not the skin, determines the rate for drug absorption. These transdermal therapeutic systems provide a predictable rate of giving drugs systemically and will maintain that rate for extended periods and so eliminate many of the variables associated with ointments and creams. ${ }^{17}$

The first transdermal therapeutic system, recently introduced in the United States, administers hyoscine at the predetermined rate of $0.5 \mathrm{mg}$ over three days for the prevention and treatment of motion sickness. Hyoscine is the most effective agent for the prevention of motion sickness 22 : given transdermally it prevents motion sickness in $75 \%$ of susceptible patients. ${ }^{23}$ The flow of saliva is transiently reduced, but other recognised parasympatholytic effects of the drug are infrequent or rare. In contrast, giving hyoscine hydrobromide by mouth for the prevention of motion sickness usually produces tachycardia, profound reduction in salivary flow, drowsiness, and occasionally effects on the central nervous system.

This new dosage form is a small, circular, adhesive film $2.5 \mathrm{~cm}^{2}$ in area and $18 \mathrm{~mm}$ in diameter. It is designed for application behind the ear, where favourable skin permeation properties ensure that the rate of the drug released from the system determines the rate of entry into the circulation. ${ }^{24}$ The inner adhesive face of the product is applied to the skin after removal of a protective liner, as with an ordinary adhesive bandage. The crucial control of the rate is provided by a microporous membrane interposed between the drug reservoir and the adhesive. Though the system looks like a single-layered film, it consists of four layers laminated together: from outside in, an impermeable flesh-coloured surface, a reservoir of drug, a microporous, rate-controlling membrane, and an adhesive, which contains a small quantity of drug for immediate absorption. The system's design is based on knowledge of the skin-permeation properties of hyoscine. Release of the drug occurs by diffusion from the reservoir, through the ratecontrolling membrane and adhesive to the skin surface, which can absorb the drug at rates many times higher than that at which the system's membrane allows the drug to be released. For full efficacy, the system should be applied several hours before exposure to motion, but it may also halt motion sickness, because the drug is effectively absorbed even if the patient is vomiting. 